\title{
Die Genfer Ärztegesellschaft
}

Pierre-Alain Schneider

Präsident AMG

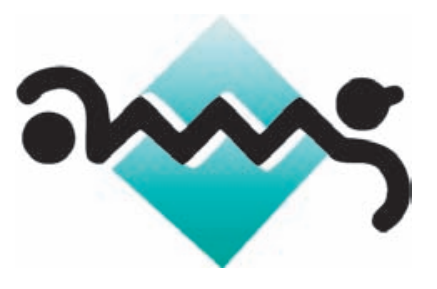

Genf weist einige Besonderheiten auf, die oft missverstanden werden. Der Kanton an der Peripherie des schweizerischen Staatsgebiets liegt im Zentrum einer grenzüberschreitenden Agglomeration mit fast 800000 Einwohnern. Auf einem winzigen Gebiet ( $0,6 \%$ der Landesfläche) bietet er $8 \%$ der Arbeitsplätze der Schweiz. Und trotz einer sehr weltoffenen Bevölkerung mit einem Ausländeranteil von 38\% fühlt sich Genf als zutiefst schweizerisch und ist stolz auf diese $\mathrm{Zu}$ gehörigkeit. Dies hindert den Kanton allerdings nicht daran, den Bund bei jeder Gelegenheit zu kritisieren...

Das aussergewöhnliche Verhältnis von 300000 Arbeitsplätzen auf 450000 Einwohner wird dank 50000 Grenzgängern und zahlreichen Pendlern aus dem Waadtland erreicht. Der Grund dafür ist der teure Wohnraum in Genf, wo die Wohnungssuche einem Hindernislauf gleichkommen kann. Genfs zahlreiche Gesichter - von Calvin über das Web und das Rote Kreuz bis zum schwarzen Loch, das uns gemäss einigen Propheten nach der Herstellung des Higgs-Teilchens verschlingen könnte - werden von seinen Einwohnern oft nicht beachtet.

Die Gründung der Genfer Ärztekammer (Société médicale de Genève) geht auf das Jahr 1823 zurück. Nach und nach ersetzte die wissenschaftlich ausgerichtete Ärztekammer die drei früheren Gesellschaften für Chirurgie, für Medizin sowie für Medizin und Chirurgie. Sie stellte einen sehr exklusiven Klub dar: 1887 gehörten ihr nur 41 der 96 in Genf gemeldeten Ärzte an.

Ende des 19. Jahrhunderts erlebte die Stadt eine ausserordentlich rasche Entwicklung, und ihre Bevölkerung verdoppelte sich in weniger als 50 Jahren. Die Neuankömmlinge, oft Kleingewerbler ohne Vermögen, standen mittellos da, wenn sie krank wurden. Ein Viertel der Arzthonorare wurde deshalb nie beglichen, was einige Ärzte in eine schwierige Lage brachte. In dieser Situation erschien es notwendig, eine Gesellschaft zur Vertretung der Standesinteressen der Ärzteschaft zu gründen.

1892 wurde daher die Genfer Ärztegesellschaft (Association des médecins du canton de Genève, AMG) gegründet. Sie verfolgte den Zweck, die Standesinteressen ihrer Mitglieder zu vertreten und die ärztliche Würde zu wahren. Parallel dazu führte die Genfer Ärztekammer ihre wissenschaftlichen Aktivitäten bis heute fort. Die AMG intervenierte umgehend beim Staatsrat, um die Organisation einer medizinischen Versorgung zu verlangen, die der Bundesverfassung entspricht. Die Ärzte behandelten damals gewisse mittellose Personen unentgeltlich, doch da deren Zahl nun zu hoch war, konnte dies nicht so weitergehen. Das erste Kranken- und Unfallversicherungsgesetz, die Lex Forrer, wurde 1900 vom Volk abgelehnt. Erst 1914 trat das KUVG in Kraft, das unterdessen vom KVG abgelöst wurde.

Seit ihren Anfängen hat sich die AMG unablässig für die Standesinteressen der Genfer Ärztinnen und Ärzte eingesetzt. Sie zählt heute über 2000 Mitglieder, davon 1750 Aktivmitglieder. Ihr gehören somit fast alle niedergelassenen Ärzte und zahlreiche Spitalärzte an. Vom Ärztemangel waren die dem Zulassungsstopp unterstehenden Privatpraxen bisher kaum betroffen. Er trifft vielmehr die öffentlichen Spitäler, die ihren Auftrag ohne den Zustrom von ausländischen Ärzten und Pflegenden - nicht mehr wahrnehmen könnten. Und wie im 19. Jahrhundert ist die immer schwierigere Situation, in der Ärztinnen und Ärzte ihren Beruf ausüben müssen, auch heute eine der wichtigsten Fragen, die die AMG beschäftigen. 